\title{
In Situ X-ray Raman Scattering Spectroscopy of the Formation of Cobalt Carbides in a $\mathrm{Co} / \mathrm{TiO}_{2}$ Fischer-Tropsch Synthesis Catalyst
}

José G. Moya-Cancino, Ari-Pekka Honkanen, Ad M. J. van der Eerden, Ramon Oord, Matteo Monai, Iris ten Have, Christoph J. Sahle, Florian Meirer, Bert M. Weckhuysen, Frank M. F. de Groot,* and Simo Huotari*

Cite This: ACS Catal. 2021, 11, 809-819

Read Online

ACCESS | Llll Metrics \& More | 回 Article Recommendations ｜（s Supporting Information

ABSTRACT: We present in situ experiments to study the possible formation of cobalt carbides during Fischer-Tropsch synthesis (FTS) in a $\mathrm{Co} / \mathrm{TiO}_{2}$ catalyst at relevant conditions of pressure and temperature. The experiments were performed by a combination of X-ray Raman scattering (XRS) spectroscopy and X-ray diffraction (XRD). Two different experiments were performed: (1) a FischerTropsch Synthesis (FTS) reaction of an $\sim 14$ wt $\% \mathrm{Co} / \mathrm{TiO}_{2}$ catalyst at $523 \mathrm{~K}$ and 5 bar under $\mathrm{H}_{2}$ lean conditions (i.e., a $\mathrm{H}_{2}: \mathrm{CO}$ ratio of 0.5 ) and (2) carburization of pure cobalt (as reference experiment). In both experiments, the Co $\mathrm{L}_{3}$-edge XRS spectra reveal a change in the oxidation state of the cobalt nanoparticles, which we assign to the formation of cobalt carbide $\left(\mathrm{Co}_{2} \mathrm{C}\right)$. The $\mathrm{C} \mathrm{K}$ edge XRS spectra were used to quantify the formation of different carbon species in both experiments.

KEYWORDS: X-ray spectroscopy, Fischer-Tropsch synthesis, heterogeneous catalysis, cobalt carbide, catalyst deactivation

\section{INTRODUCTION}

Fischer-Tropsch Synthesis (FTS) technology enables the production of long-chain hydrocarbons as synthetic fuels from fossil (e.g., coal and natural gas) and renewable feedstock (e.g., biomass and municipal waste). In the FTS process, a mixture of carbon monoxide $(\mathrm{CO})$ and hydrogen $\left(\mathrm{H}_{2}\right)$ is converted into different hydrocarbons by a catalytic surface polymerization reaction. ${ }^{1}$ Iron and cobalt-based FTS catalysts are the most relevant for industrial applications, where a Co-based catalyst is more used for processing syngas derived from natural gas and possesses a higher selectivity toward liquid hydrocarbons $\left.\left(\mathrm{C}_{5+}\right)\right)^{2,3}$ However, the gradual deactivation of Co-based FTS catalyst materials is one of the main concerns in the FTS research. The deposition of carbon species, typically called coke (e.g., graphitic, aliphatic, or aromatic) onto the catalyst surface as well as the sintering of supported cobalt nanoparticles are the most significant aspects of deactivation. ${ }^{4,5}$ In addition, the formation of cobalt carbides (e.g., bulk, sub-surface, and surface) derived from the carbon deposition is a controversial topic. Some studies correlate its formation with the deactivation process of the catalyst, ${ }^{6-8}$ while other groups relate it with a higher selectivity toward lower olefins, , 10 as an intermediate species during the FTS reaction, ${ }^{11,12}$ and an active species for the water gas shift (WGS) reaction and oxygenate selectivity. ${ }^{13,14}$ Clearly, more research is needed to resolve this debate in the literature.
Advances of various in situ and operando synchrotron techniques have resulted in comprehensive studies on the coke formation over a $\mathrm{TiO}_{2}$-supported cobalt catalyst during FTS reaction, ${ }^{15}$ the influence of $\mathrm{Mn}$ and $\mathrm{Re}$ as promotor elements on $\mathrm{Co} / \mathrm{TiO}_{2}$ and $\mathrm{Co} / \mathrm{Zr} / \mathrm{SiO}_{2}$ FTS catalysts, ${ }^{16-18}$ the effect of the particle size and the formation of carbides on $\mathrm{Al}_{2} \mathrm{O}_{3^{-}}$ supported Co FTS catalysts, ${ }^{19}$ among others. Additionally, in situ studies on carbide formation using laboratory and synchrotron-based setups have been performed on different cobalt-based catalysts. ${ }^{8,20-24}$ Despite these advances and the characterization studies performed, our fundamental understanding of the effect of carbide species on the performance of the FTS catalyst still remains rather limited. ${ }^{1,4,5}$ Hence, other characterization methods should be called in.

X-ray Raman scattering (XRS) spectroscopy is a photon-in/ photon-out probe where inelastic scattering of hard $(\sim 10 \mathrm{keV})$ $\mathrm{X}$-rays is used to probe core-level electron excitations. Using this $\mathrm{X}$-ray energy loss method, information equivalent to soft X-ray

Received: October 19, 2020

Revised: December 10, 2020

Published: January 4, 2021 


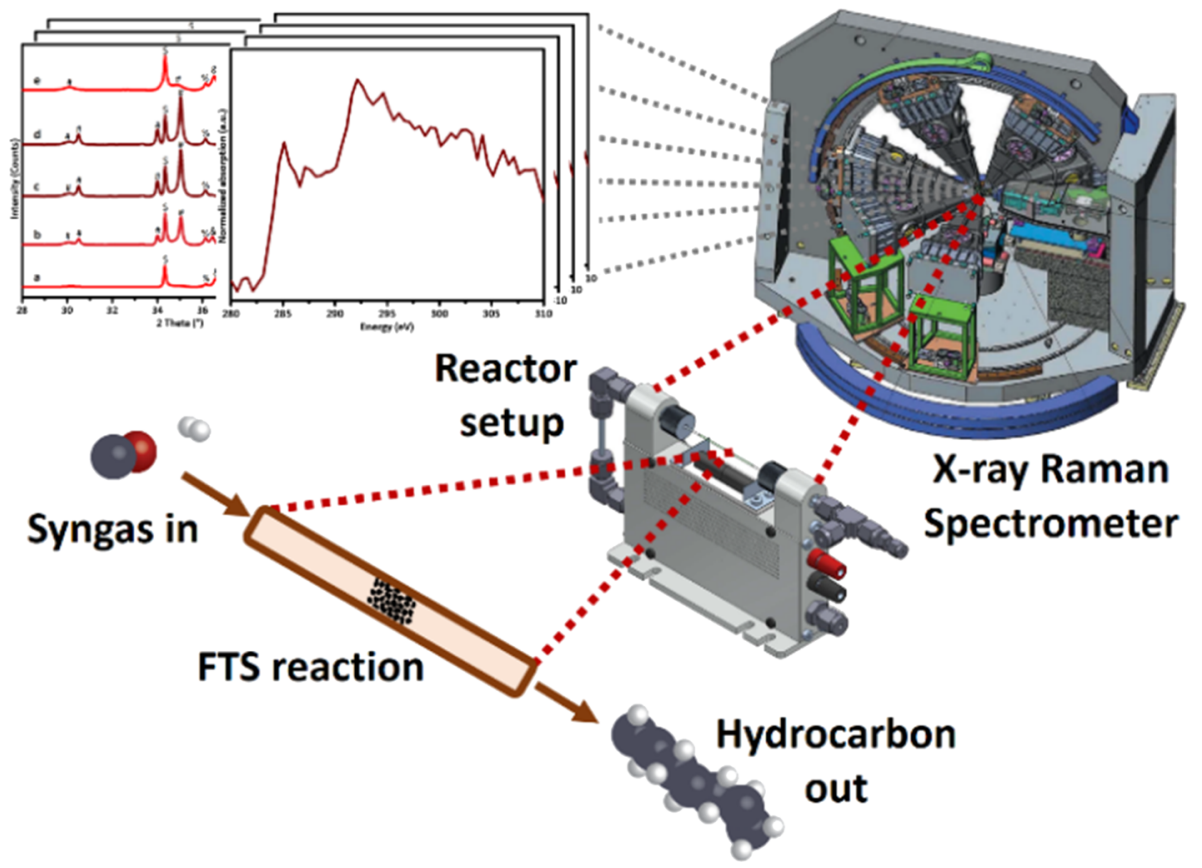

Figure 1. Schematic of the in situ configuration used for combined X-ray Raman scattering (XRS) spectroscopy and X-ray diffraction (XRD) experiments on a $\mathrm{Co} / \mathrm{TiO}_{2}$ Fischer-Tropsch synthesis catalyst. ${ }^{25}$
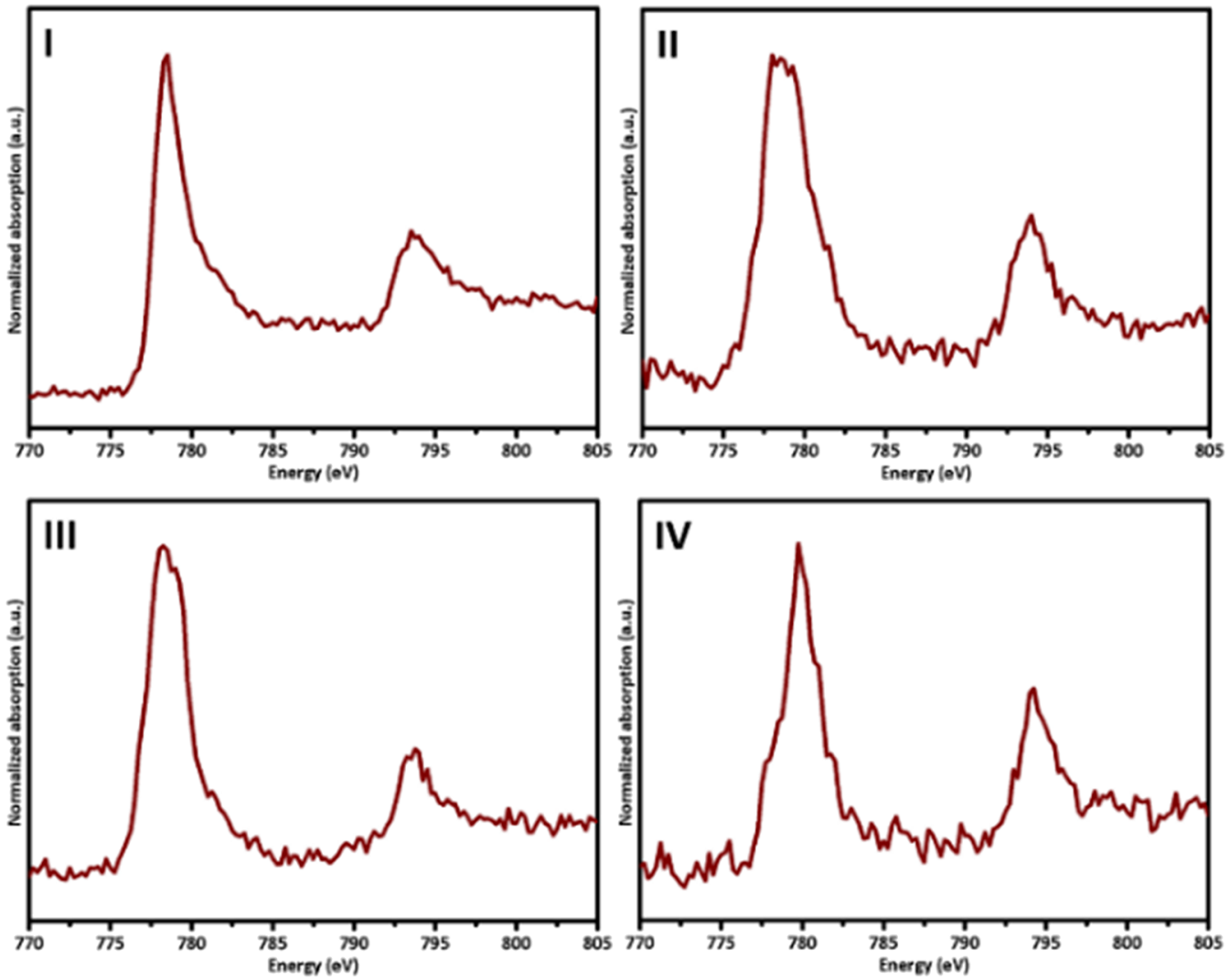

Figure 2. $\mathrm{Co}_{2,3}$ edges spectra for various reference samples: (I) Co foil, (II) $\mathrm{CoO}$, (III) $\mathrm{CoTiO}_{3}$, and (IV) $\mathrm{Co}_{3} \mathrm{O}_{4}$.

absorption spectroscopy can be obtained, ${ }^{25-29}$ allowing to measure the spectroscopic fingerprints of the $\mathrm{Co}_{2,3}$ edges and $\mathrm{C} \mathrm{K}$ edge, which are relevant for the study of $\mathrm{Co} / \mathrm{TiO}_{2}$ FTS catalysts. The principle is the same as in electron energy-loss near-edge spectroscopy (ELNES), but since hard X-rays are used as a probe, most constraints on sample environments are lifted and experiments can be done under in situ conditions such as those required during the FTS reaction. Hence, we present here an in situ study that combines XRS and X-ray diffraction (XRD) to study the FTS reaction at relevant conditions of pressure and temperature (i.e., 5 bar and $523 \mathrm{~K}$ ). This new analytical approach was used to elucidate the formation of cobalt 
carbides during FTS reaction within an unpromoted $\mathrm{Co} / \mathrm{TiO}_{2}$ catalyst.

\section{RESULTS AND DISCUSSION}

The experiments described were performed at the ID20 beamline of the European Synchrotron Radiation Facility (ESRF), which hosts an end station dedicated for XRS. ${ }^{30}$ The used spectrometer has 72 spherically bent crystal analyzers with the $\mathrm{Si}(660)$ reflection, organized in six modules with 12 analyzers each. ${ }^{30}$ For the XRD data collection, a Pilatus $300 \mathrm{~K}-\mathrm{W}$ detector was used. The photon energy at the zero loss line was $9.7 \mathrm{keV}$. The in situ configuration of the combined XRS and $\mathrm{XRD}$ experiments is illustrated in Figure 1.

First, we measured the $\mathrm{Co} \mathrm{L}_{2,3}$ edges of metallic Co, CoO, $\mathrm{CoTiO}_{3}$, and $\mathrm{Co}_{3} \mathrm{O}_{4}$, as reference cobalt materials. They were used to identify the different cobalt species (i.e., during the activation process of cobalt, $\mathrm{Co}_{3} \mathrm{O}_{4} \rightarrow \mathrm{CoO} \rightarrow \mathrm{Co}^{0}$ ) formed at different stages of the in situ reactions. Figure 2 depicts the spectra of the different cobalt references.

The first experiment performed was an in situ carburization reaction (control experiment) of pure cobalt nanoparticles at $523 \mathrm{~K}$ and 5 bar of $\mathrm{CO}$. At the end of the experiment, the sample was re-hydrogenated $\left(1 \mathrm{~mL} / \mathrm{min}\right.$ of $\mathrm{H}_{2}$ for $\left.\sim 1 \mathrm{~h}\right)$ and the $\mathrm{Co}_{2} \mathrm{C}$ formed was back-converted to metallic $\mathrm{Co}$. This experiment was done to identify the main features of the spectra of the carburized sample. We expect the $\mathrm{Co}_{2,3}$ edges to change shape owing to the change of oxidation state upon the formation of cobalt carbide $\left(\mathrm{Co}_{2} \mathrm{C}\right)$. The normalized and background subtracted in situ Co $\mathrm{L}_{2,3}$ edges spectra obtained during the carburization reaction are presented in Figure 3. During the

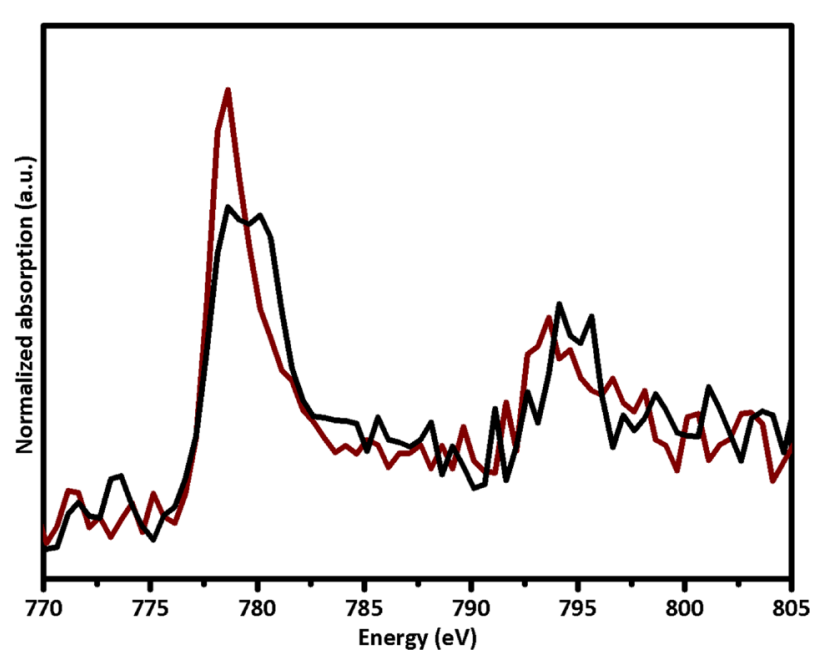

Figure 3. In situ $\mathrm{Co}_{2,3}$ edges for the carburization reaction of pure Co nanoparticles at $523 \mathrm{~K}$ and $5 \mathrm{bar}$, the spectrum of reduced cobalt oxide (metallic $\mathrm{Co}$ ) in red and the spectrum after carburization in black.

carburization reaction, a distinct change in the $\mathrm{Co}_{2,3}$ edges spectrum can be identified. Upon carburization, the spectral weight shifts toward higher energies and the $\mathrm{L}_{3}$ edge at $780 \mathrm{eV}$ becomes broader. This can be attributed to the changing oxidation state of $\mathrm{Co}$, most likely in this experiment owing to the formation of $\mathrm{Co}_{2} \mathrm{C}$, which is considered to be the most stable cobalt carbide under FTS conditions.

A second experiment performed was an in situ FTS reaction of an $\sim 14$ wt $\%$ of $\mathrm{Co} / \mathrm{TiO}_{2}$ catalyst at $523 \mathrm{~K}$ and 5 bar, using a $\mathrm{H}_{2}$ :CO ratio of $0.5\left(0.5 \mathrm{~mL} / \mathrm{min}\right.$ of $\mathrm{H}_{2}$ and $1 \mathrm{~mL} / \mathrm{min}$ of $\left.\mathrm{CO}\right)$. The latter represent $\mathrm{H}_{2}$ lean reaction conditions to enhance the deactivation process of the catalyst (the FTS reaction is performed normally at a $\mathrm{H}_{2}: \mathrm{CO}$ ratio of 2). The FTS reaction was performed for $15 \mathrm{~h}$. Figure 4 shows the different $\mathrm{Co}_{3}$ edges

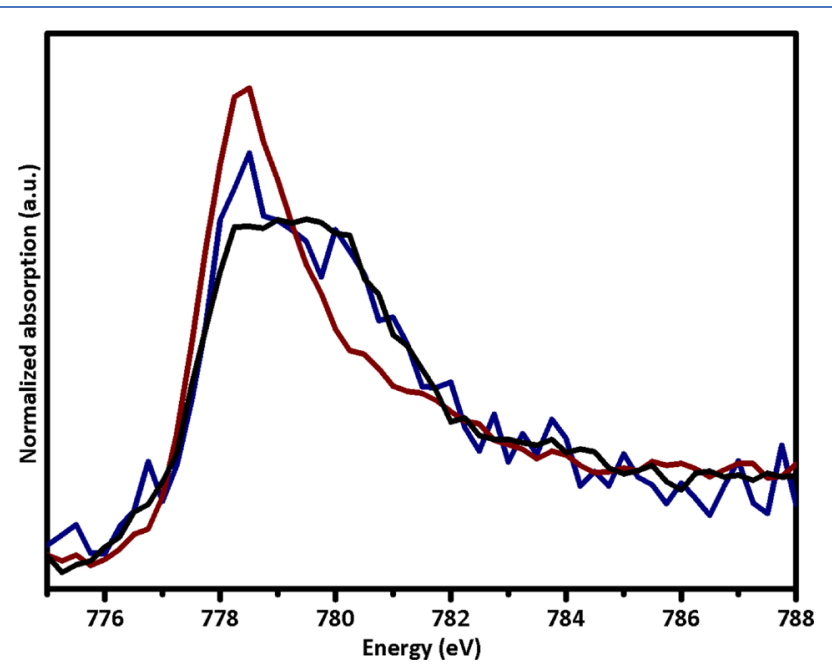

Figure 4. In situ $\mathrm{Co}_{3}$ edge for the FTS reaction over a $\mathrm{Co} / \mathrm{TiO}_{2}$ catalyst at $523 \mathrm{~K}$ and 5 bar (with a $\mathrm{H}_{2}: \mathrm{CO}$ ratio of 0.5 ) compared to the spectra of the Co metal reference and the carburized sample. FTS sample, blue; Co metal reference, dark red; and carburized sample, black.

of the Co metal reference and the carburized samples obtained in the in situ experiment compared to the spectrum collected during FTS for $15 \mathrm{~h}$. We report here only the $\mathrm{Co}_{3}$ edge because this edge presents the characteristic shift produced by the $\mathrm{Co}_{2} \mathrm{C}$. Instead, the $\mathrm{Co}_{2}$ edge did not provide sufficient information about the oxidation state of the samples. The full spectrum obtained during FTS is presented in Figure S1 in the Supporting Information.

From the Co $\mathrm{L}_{2,3}$ edge analysis, it was confirmed that the catalyst was reduced to metallic cobalt (the active phase of cobalt for the FTS reaction) after the activation process. ${ }^{4,8,16}$ During the FTS reaction at $523 \mathrm{~K}$ and 5 bar, we obtained a Co $\mathrm{L}_{3}$ edge spectrum that presents similar characteristics to that obtained during the carburization reaction (i.e., no further reoxidation into $\mathrm{CoO}$ and subsequent $\mathrm{Co}_{3} \mathrm{O}_{4}$ was observed during the reaction). This was taken as a conclusive in situ evidence of the formation of $\mathrm{Co}_{2} \mathrm{C}$ also during the FTS reaction, which agrees with previous works performed in our research group. ${ }^{3,21}$

In the case of the $\mathrm{C} \mathrm{K}$ edge measurements, graphite powder, pyrene, as well as SX-70 and SX-100 (FTS waxes) were measured as carbon standard materials. Figure 5 shows the spectra of these reference samples. Also, electron energy loss spectra from amorphous graphite ${ }^{31}$ and carbon monoxide ${ }^{32-34}$ are included and broadened via a convolution by a Gaussian for the total linewidth to match our $0.7 \mathrm{eV}$ energy resolution. In case of the in situ carburization reaction, Figure 6I illustrates the in situ carbon spectrum collected at the beginning and during $10 \mathrm{~h}$ of carburization.

The spectrum at the beginning of the carburization shows no relevant intensity as expected from this carbon-free material. However, a distinct spectrum of the $\mathrm{C} \mathrm{K}$ edge is clearly visible after $10 \mathrm{~h}$ of carburization. The $\mathrm{C} \mathrm{K}$ edge is expected to reveal the formation of a number of carbonaceous condensed-phase products, e.g. coke, in addition to the $\mathrm{Co}_{2} \mathrm{C}$ formed. From the spectrum of the carburized sample, an absorption band can be observed at $\sim 285 \mathrm{eV}$ that corresponds to the $1 \mathrm{~s} \rightarrow \pi^{*}$ transition, 

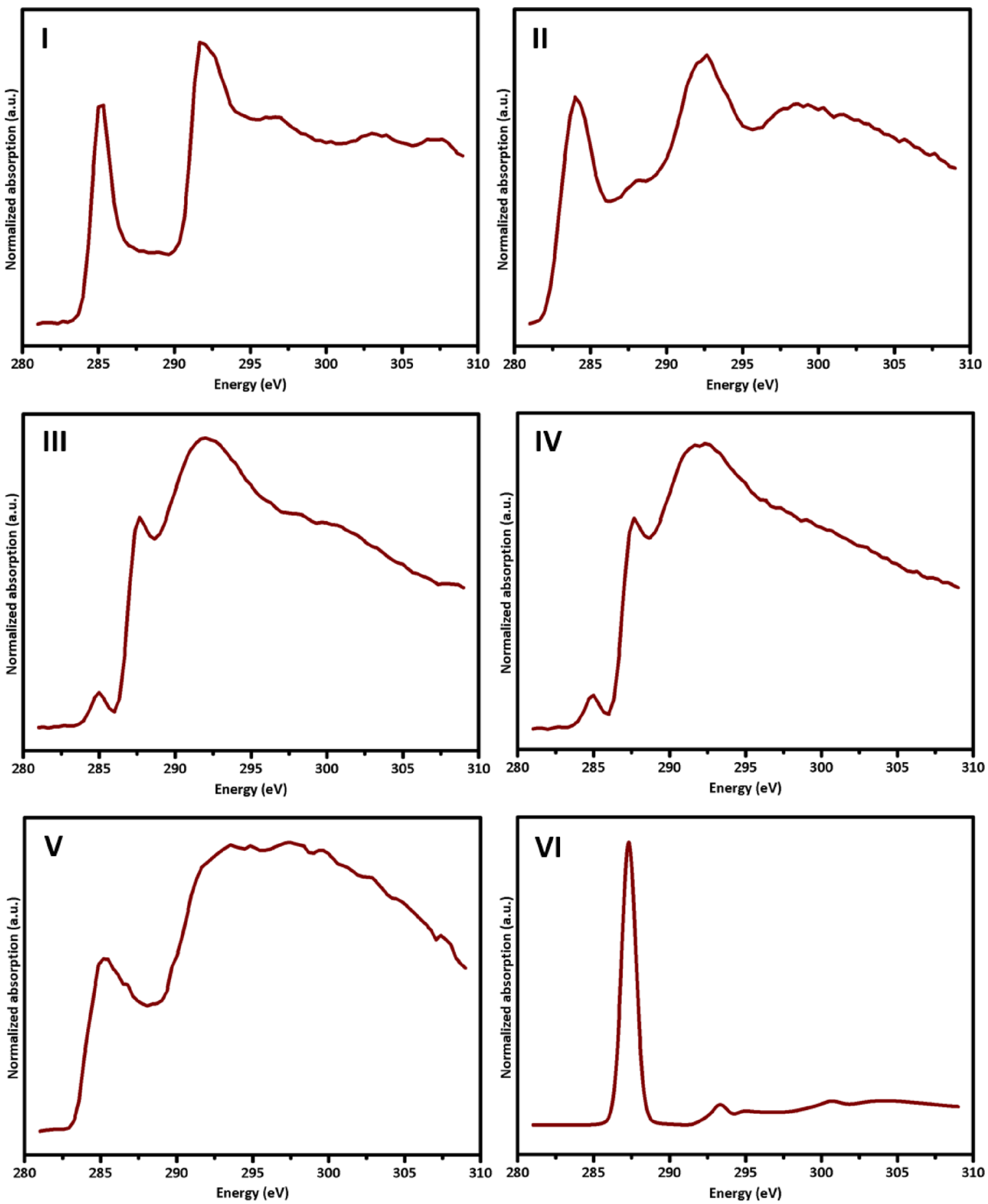

Figure 5. C K edge spectra for reference samples: (I) graphite, (II) pyrene, (III) SX-70, (IV) SX-100, (V) amorphous graphite, and (VI) carbon monoxide. $^{31-34}$

which evidences the presence of aromatic rings $(\mathrm{C}=\mathrm{C}) .{ }^{35-38}$ The absorption band observed at $\sim 287 \mathrm{eV}$ corresponds to the 1 $\mathrm{s} \rightarrow \pi^{*}$ transition, assigned to $\mathrm{C}=\mathrm{O}$ that could be ascribed to the carbon monoxide from the gas phase. ${ }^{39}$ In addition, an absorption band at $\sim 292 \mathrm{eV}$ was detected, corresponding to the $1 \mathrm{~s} \rightarrow \sigma^{*}$ transition in aromatic $\mathrm{C}-\mathrm{C} . .^{35,37,38,40}$ From the analysis of the $\mathrm{C} \mathrm{K}$ edge spectrum, one can establish that the carburized sample exhibits characteristics of graphitic carbon. By integrating over the $\mathrm{C} \mathrm{K}$ edge spectra between 280 and 310 $\mathrm{eV}$, it was possible to quantify the amount of carbon formed as a function of the reaction time. The result of this analysis is given in Figure 6II. The last time step corresponds to the beginning of the re-hydrogenation step, where the amount of carbon was expected to decrease, which indeed is evidenced by the data obtained.

A similar trend was observed for the in situ FTS reaction. Figure 7 presents the $C \mathrm{~K}$ edge spectrum acquired during $15 \mathrm{~h}$ of FTS reaction and the amount of carbon formed during the FTS reaction at $523 \mathrm{~K}$ and 5 bar. As in the case of the $\mathrm{C} \mathrm{K}$ edge spectrum from the carburization experiment, absorption bands were observed at $\sim 285 \mathrm{eV}, 1 \mathrm{~s} \rightarrow \pi^{*}$ transition, ${ }^{35-38}$ at $\sim 287 \mathrm{eV}$, $1 \mathrm{~s} \rightarrow \pi^{*}$ transition, $^{39}$ and at $\sim 292 \mathrm{eV}, 1 \mathrm{~s} \rightarrow \sigma^{*}$ 

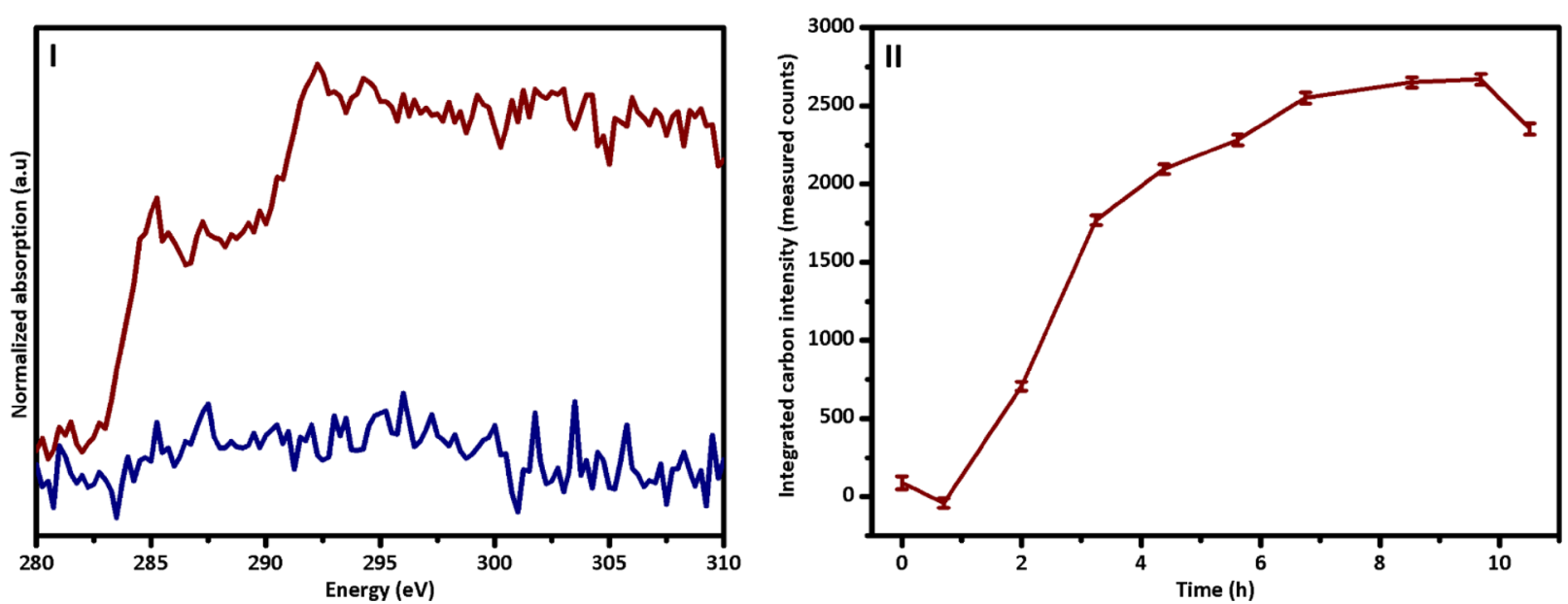

Figure 6. (I) In situ $\mathrm{C}$ K edge for the carburization reaction of pure Co nanoparticles at $523 \mathrm{~K}$ and 5 bar, spectrum at the beginning of the carburization reaction in blue and carburized spectrum in dark red. (II) Carbon evolution during the carburization reaction (the last point correspond to the rehydrogenation step). Error bars are based on the statistical uncertainties, see Section S2 in the Supporting Information.
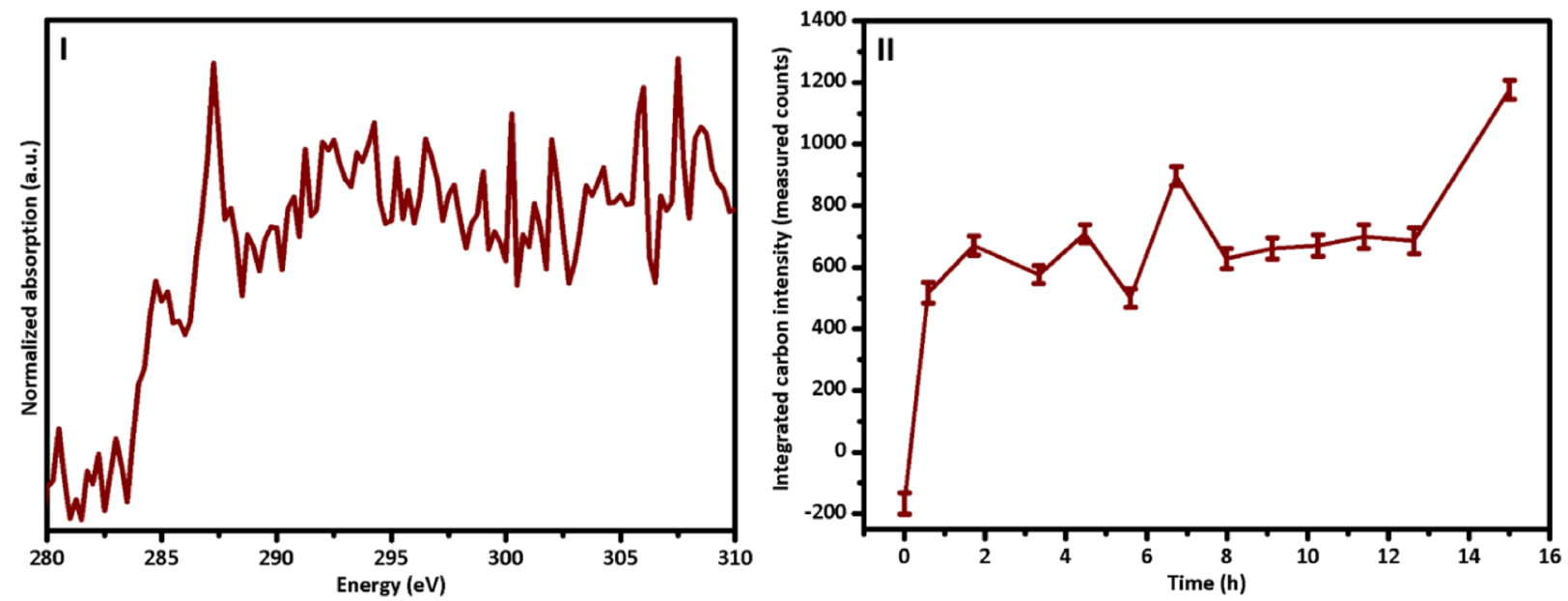

Figure 7. (I) In situ $\mathrm{C}$ K edge for the FTS reaction over a $\mathrm{Co} / \mathrm{TiO}_{2}$ catalyst at $523 \mathrm{~K}$ and 5 bar, and for $15 \mathrm{~h}$ of reaction with a $\mathrm{H}_{2}$ : $\mathrm{CO}$ ratio of 0.5 . (II) Amount of carbon evolved during the FTS reaction. Error bars are based on the statistical uncertainties. Further systematic uncertainty arises especially below the FTS onset due to Compton background subtraction, but it is not included in the error bars, see Section S2.
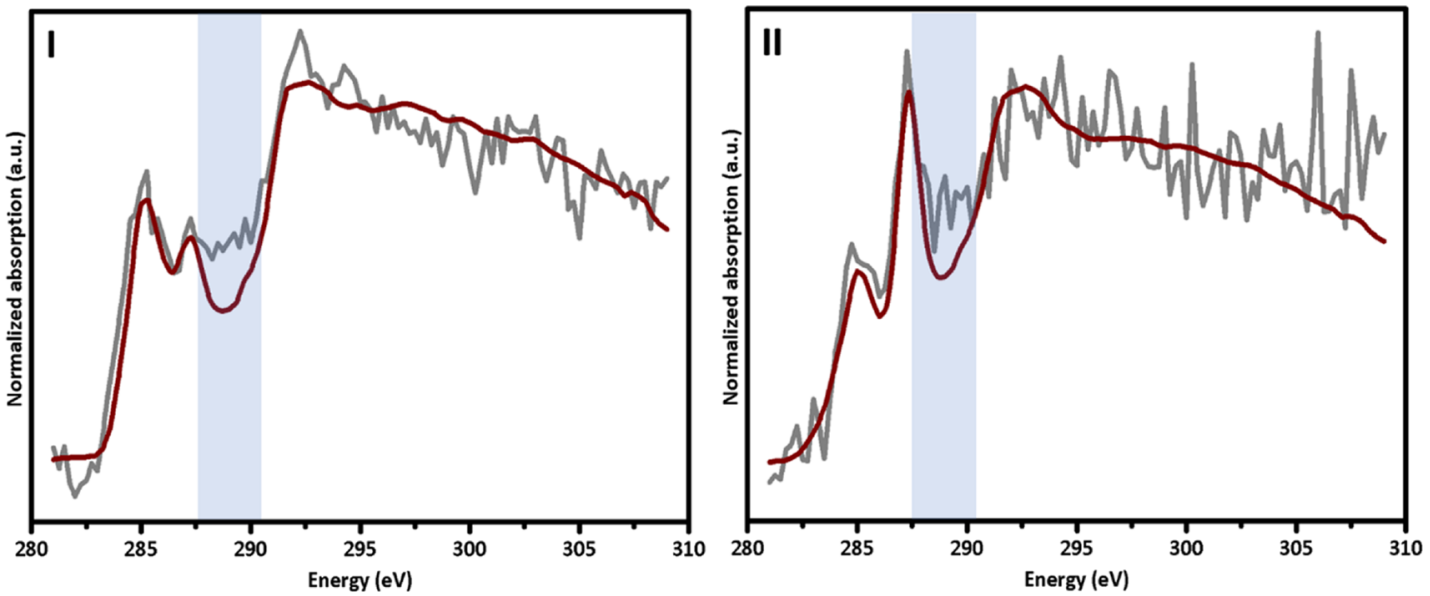

Figure 8. (I) Carburization reaction of C K edge data and calculated fit, and (II) FTS reaction of C K edge data and calculated fit. The details of the fit and the resulting spectral compositions are explained in the main text. The experimental spectrum in gray and fitting data in dark red. The shaded region marks the energy where the agreement between the fit and the experiment are not explained by the used reference standards.

transition. ${ }^{35,37,38,40}$ From the analysis of the data obtained, it was established that during the FTS reaction, graphitic species were deposited on the active phase of the $\mathrm{Co} / \mathrm{TiO}_{2}$ catalyst. The relative intensity at $\sim 287 \mathrm{eV}$ (i.e., $\mathrm{CO}$ in the gas phase) was 
more pronounced than in the case of the carburization experiment because of the reduced amount of carbon species formed and deposited during the FTS reaction.

Finally, to identify and quantify the different carbon species presented during the carburization and FTS reactions, the $\mathrm{C} \mathrm{K}$ edge spectra were fitted to the measured reference components using the least-squares method. The fit was done using the areanormalized spectra of graphite, carbon monoxide, pyrene, amorphous graphite, and SX-70 in the case of the FTS reaction, while for the carburization reaction the SX-70 and pyrene were left out from the fit as their formation is not possible in that reaction. The area normalization was done for the range 280$310 \mathrm{eV}$. The spectra of SX-70 and SX-100 (see Figure 5) were so similar that using both of them in the fit was not justified, hence, SX-70 represents the total waxes contribution for the purpose of the least-squares fit. The aim of the fits is to represent the areanormalized experimentally observed C K edge spectrum $S(E)$ as a linear combination of individual components spectra $S_{i}(E)$ with weight fractions $c_{i}$, i.e., $S(E)=\sum_{i} c_{i} S_{i}(E)$. The fit results are shown in Figure 8. Overall, using these carbon reference species produces an excellent agreement with the fit and the experimental $\mathrm{C} \mathrm{K}$ edge spectra. The spectral weight compositions $c_{i}$ obtained for the carburization reaction were $66 \%$ amorphous graphite, $30 \%$ crystalline graphite with $4 \%$ carbon monoxide present owing to the gas flow. In the case of the FTS reaction, the composition obtained was 34\% amorphous graphite, 23\% SX waxes, $17 \%$ crystalline graphite, $15 \%$ pyrene, and with a spectral contribution of $11 \%$ carbon monoxide.

Interestingly, certain level of disagreement between the fit and both experiments at $\sim 288 \mathrm{eV}$ energy transfer region remains, with an apparent spectral weight observed in the experiment at that energy not explained by the fit. To model if this disagreement could be assigned to the formation of $\mathrm{Co}_{2} \mathrm{C}$, we calculated the expected $\mathrm{C} \mathrm{K}$ spectrum of $\mathrm{Co}_{2} \mathrm{C}$ using $\mathrm{FEFF}$ software. ${ }^{41-43}$ The results of the FEFF calculation for $\mathrm{C} \mathrm{K}$ edge spectra of $\mathrm{Co}_{2} \mathrm{C}$ and calculation for graphite using the same method are shown in Figure 9. The energy scale of the calculated spectra is shifted rigidly so that the first peak of the graphite spectrum is at the experimentally observed energy $(285 \mathrm{eV})$. Interestingly, the spectrum of $\mathrm{Co}_{2} \mathrm{C}$ shows a strong peak close to the energy region that exhibits the disagreement between the

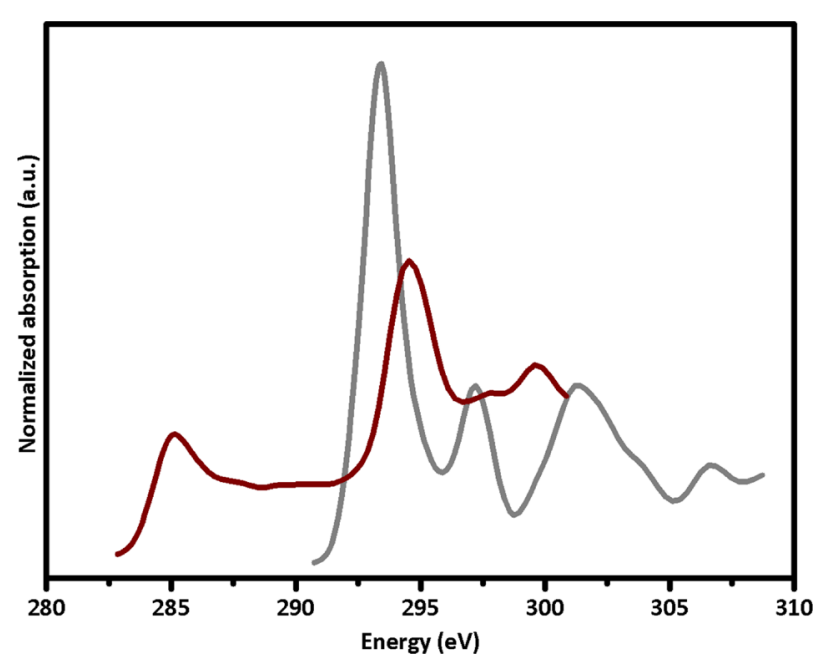

Figure 9. Calculated XANES spectra of graphite and $\mathrm{Co}_{2} \mathrm{C}$ using FEFF. $\mathrm{Co}_{2} \mathrm{C}$ in gray and graphite in dark red. experiment and the fit in Figure 8. We thus assign the remaining spectral weight at $288 \mathrm{eV}$ in the spectrum obtained from the experiment to the formation of $\mathrm{Co}_{2} \mathrm{C}$. The agreement between the calculated and measured spectra of graphite does not warrant using the calculated spectra in the fit as a spectral component, but the qualitative agreement of the experimental and calculated spectra is satisfactory. Most notably, the calculated spectra would need effectively an energy scale condensation as the $\pi^{*}$ and $\sigma^{*}$ peaks of the graphite spectrum are further apart from each other than in the experimental spectra. Based on this note and comparing the calculated and experimental $\mathrm{C} \mathrm{K}$ edge spectra, qualitatively give confidence to the assignment of the $288 \mathrm{eV}$ spectral region to originate from the formation of $\mathrm{Co}_{2} \mathrm{C}$.

Additionally, in situ XRD patterns were collected during the carburization reaction of Co nanoparticles to determine the cobalt species present in the distinctive steps of the reaction. Figure 10I shows the in situ XRD patterns collected at different reaction times. From the $\mathrm{XRD}$ analysis, it can be confirmed that at the beginning of the reaction, the cobalt was presented as metallic cobalt, and during the execution of the experiment, it was gradually converted to cobalt carbide. At the end of the carburization reaction, the sample was re-hydrogenated. During the reaction, the hcp-Co phase was faster transformed into $\mathrm{Co}_{2} \mathrm{C}$, while a fraction of the fcc-Co phase remained metallic during the course of the experiment. This agrees with information previously reported in the literature. ${ }^{21}$ Figure 10II presents the ratio between the specific intensities of $\mathrm{Co}_{2} \mathrm{C}$, fcc$\mathrm{Co}$, and hcp-Co peaks, and the intensity of the $\mathrm{BN}$ reference peak at $\sim 34^{\circ}$, called as normalized relative intensity, during the in situ carburization reaction. The data confirms the fast transformation of hcp-Co into $\mathrm{Co}_{2} \mathrm{C}$ and the more stable fcc-Co phase during the reaction.

In addition, a relation was found between the conversion of the cobalt metal into $\mathrm{Co}_{2} \mathrm{C}$ and the spatial position along the reactor. Figure 11 shows an image of the capillary reactor and XRD measurements performed at different positions in the reactor bed during $6 \mathrm{~h}$ of carburization reaction. ${ }^{44}$ It can be concluded that a larger conversion rate was observed at the beginning of the catalyst bed of the reactor, and the conversion gradually decreased with increasing distance from the gas inlet. Figure 12 shows the normalized relative intensity of the $\mathrm{Co}_{2} \mathrm{C}$, fcc-Co, and hcp-Co species at different positions along the reactor bed.

The distinct cobalt species presented during the different stages of the FTS reaction were confirmed by in situ XRD over $\mathrm{Co} / \mathrm{TiO}_{2}$ (Figure 13I). From the XRD analysis, it could be corroborated that cobalt was present as a mixture of fcc-Co and hcp-Co after the activation process $\left(\mathrm{Co}_{3} \mathrm{O}_{4} \rightarrow \mathrm{CoO} \rightarrow \mathrm{Co}^{0}\right)$. Also, a very small fraction of $\mathrm{CoTiO}_{3}$ (i.e., an inactive phase of cobalt for the FTS reaction and related to the metal-support effect) was detected after the reduction process, performed at $673 \mathrm{~K}$ and 1 bar. ${ }^{4,5}$ The presence of hot spots in the catalyst bed of the reactor could contribute to the formation of this inactive phase. ${ }^{45}$ Additionally, the evolution of $\mathrm{Co}_{2} \mathrm{C}$ (crystalline phase) during FTS reaction was observed. Figure 13II shows the normalized relative intensity of the $\mathrm{Co}_{2} \mathrm{C}$, fcc-Co, and hcp-Co species during the in situ FTS reaction, where the instability of the $\mathrm{Co}_{2} \mathrm{C}$ phase formed during the reaction was confirmed.

Stable cobalt carbide species were expected to be observed during the reaction. Those species could reduce the amount of exposed active cobalt metallic sites for the FTS reaction, which would contribute to the deactivation of the catalyst. Therefore, it 

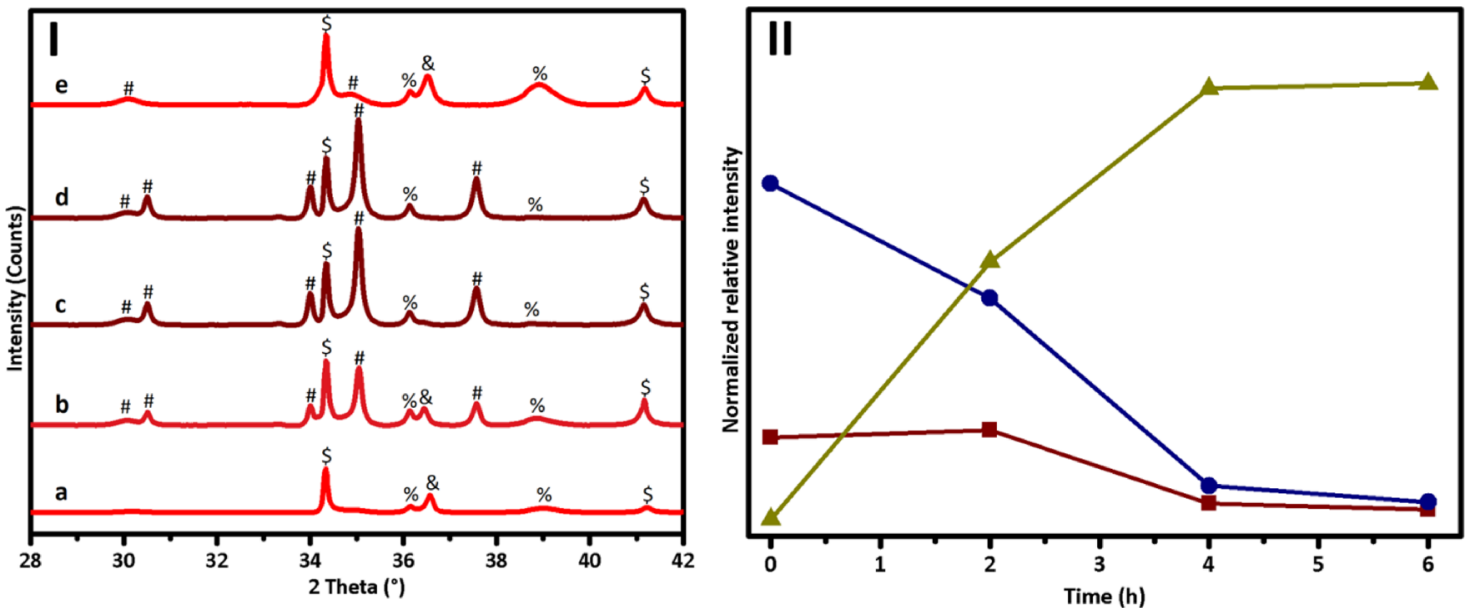

Figure 10. (I) In situ XRD patterns collected during carburization reaction of pure cobalt nanoparticles at $523 \mathrm{~K}$ and 5 bar using a pure CO flow: (a) reduced cobalt, (b) $2 \mathrm{~h}$ of carburization, (c) $4 \mathrm{~h}$ of carburization, (d) $6 \mathrm{~h}$ of carburization, and (e) re-hydrogenation of cobalt. Diffraction peaks of fccCo are marked with "\%" and hcp-Co with " $\&$ ", $\mathrm{Co}_{2} \mathrm{C}$ peaks are marked with "\#”, and boron nitride peaks are marked with "\$”. (II) Normalized relative intensity of the $\mathrm{Co}_{2} \mathrm{C}\left(35^{\circ}\right)$, fcc-Co $\left(36.1^{\circ}\right)$, and hcp-Co $\left(36.5^{\circ}\right)$ species during in situ carburization reaction. $\mathrm{Co}_{2} \mathrm{C}$ in yellow, fcc-Co in red, and hcpCo in blue.
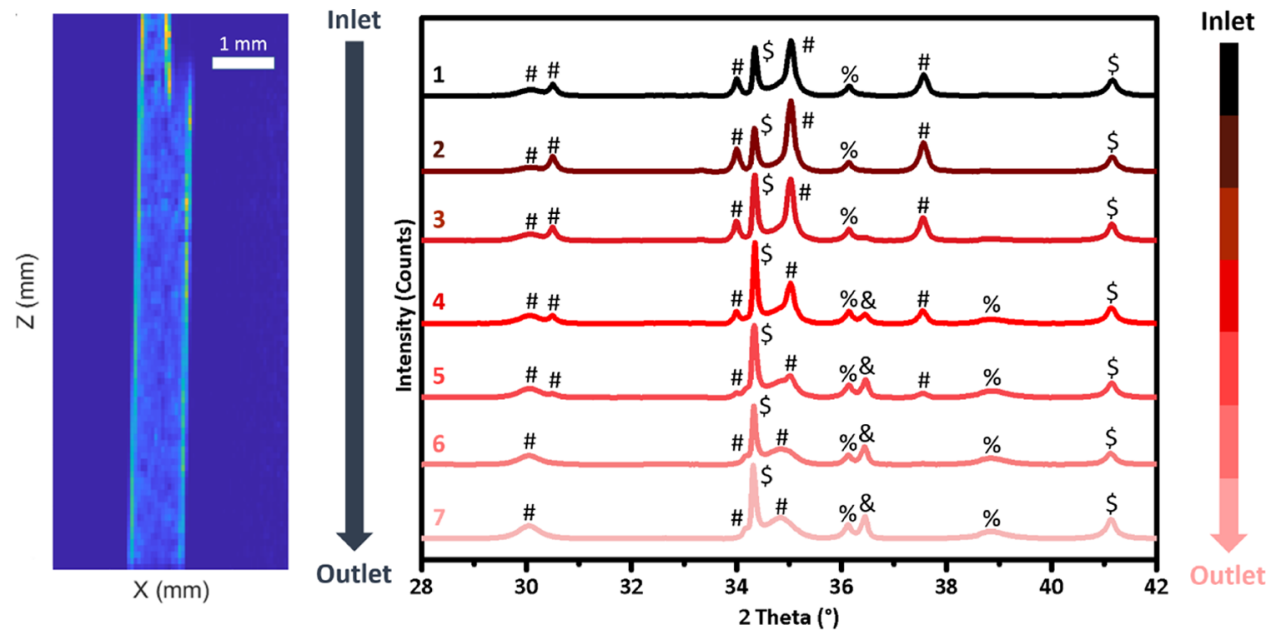

Figure 11. On the left, an image of the capillary reactor recorded during the in situ XRS experiments using the spectrometer's imaging capability. ${ }^{36}$ The probing X-ray beam that propagates along the $x$ axis and $z$ is along the cylindrical reactor bed axis. Each pixel color represents the intensity of elastic scattering as seen by one of the point-to-point focusing spherically bent analyzer crystals of the XRS spectrometer. A $10 \mu \mathrm{m}$-thick glass wall is seen as a bright scattered on the left and the intensity of scattering decreases toward the positive $\mathrm{x}$-direction because of attenuation by the sample. The thermocouple can be seen on the top to the reactor. On the right, XRD measurements performed at different positions of the bed of the capillary reactor during $6 \mathrm{~h}$ of carburization reaction, diffraction peaks of fcc-Co are marked with "\%" and hcp-Co with " $\&$ ", $\mathrm{Co}_{2} \mathrm{C}$ peaks are marked with "\#”, and boron nitride peaks are marked with “\$”.

is concluded that no direct and conclusive evidence that relates to the unstable $\mathrm{Co}_{2} \mathrm{C}$ formed during $15 \mathrm{~h}$ of FTS at $\mathrm{H}_{2}$ lean reaction conditions, can be correlated to the deactivation process of the $\mathrm{Co} / \mathrm{TiO}_{2}$ catalyst. In the case of olefins selectivity and intermediate species during the FTS reaction, the instability of the carbide formed do not provide enough evidence, and more experiments are needed to corroborate those hypothesis. $^{3,8,18-21}$

It is important to note that, the gradient along the reactor bed length, as seen in Figure 12, is typical for the plug-flow reactors, and such gradients should be taken into account before drawing conclusions about the different phenomena that take place during FTS catalyst experiments under reaction conditions.

Summarizing, we have provided evidence that cobalt carbide can be formed during FTS at 5 bar and $523 \mathrm{~K}$, but there is no direct proof that its formation relates to increased olefins selectivity, catalyst deactivation, or either that it is an intermediate species of the FTS reaction because of its instability during the reaction. $3,8,18-21$

\section{CONCLUSIONS}

By using a unique combination of in situ X-ray Raman scattering (XRS) spectroscopy and X-ray diffraction (XRD), it was possible to study cobalt carbide $\left(\mathrm{Co}_{2} \mathrm{C}\right)$ formation in pure cobalt nanoparticles. By analyzing the spectra obtained from the carburization reaction, the characteristic features were obtained for the $\mathrm{Co} \mathrm{L}$ edges and $\mathrm{C} \mathrm{K}$ edge spectra for $\mathrm{Co}_{2} \mathrm{C}$. During the FTS reaction under $\mathrm{H}_{2}$ lean conditions (i.e., a $\mathrm{H}_{2}$ : $\mathrm{CO}$ ratio of 0.5 ) of a Co/ $\mathrm{TiO}_{2}$ catalyst at $523 \mathrm{~K}$ and $5 \mathrm{bar}$, a change in the oxidation state of the cobalt was observed during $15 \mathrm{~h}$ of reaction, which was related to the formation of cobalt carbides. The formation of $\mathrm{Co}_{2} \mathrm{C}$ was confirmed by in situ XRD. 


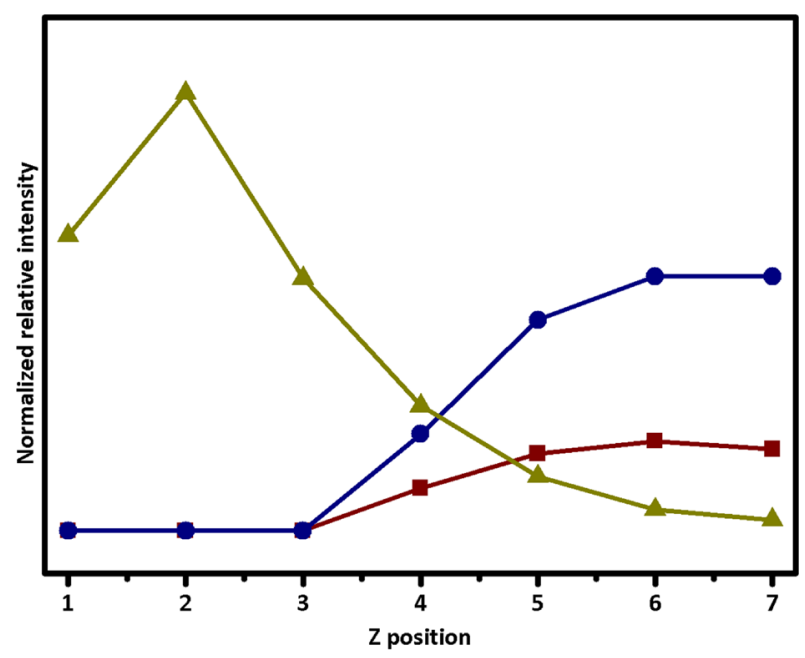

Figure 12. Normalized relative intensity of the $\mathrm{Co}_{2} \mathrm{C}\left(35^{\circ}\right)$, fcc-Co $\left(36.1^{\circ}\right)$, and $\mathrm{hcp}-\mathrm{Co}\left(36.5^{\circ}\right)$ species during $6 \mathrm{~h}$ of the in situ carburization reaction at different positions along the reactor bed. $\mathrm{Co}_{2} \mathrm{C}$ in yellow, fcc-Co in red, and hcp-Co in blue. $\mathrm{Z}$ position 1 corresponds to the measurement closer to the inlet.

Additionally, the $\mathrm{Co}_{3}$ edge and $\mathrm{C} \mathrm{K}$ edge XRS spectral analysis exhibits features that can be assigned to the carbide formation.

From the analysis, we could conclude that the instable $\mathrm{Co}_{2} \mathrm{C}$ formed, which degrades to metallic $\mathrm{Co}$ and graphite, ${ }^{7,8,12}$ cannot be correlated to the deactivation process of the $\mathrm{Co} / \mathrm{TiO}_{2}$ catalyst, olefins selectivity, or intermediate species of the FTS reaction. $^{6-11}$ The results obtained demonstrate that XRS is a powerful technique that allows measuring the $\mathrm{Co}_{2,3}$ edges and $\mathrm{C} \mathrm{K}$ edge (edges present in the soft X-rays range) at high pressure and high temperature by using hard X-rays, which represents an advantage for the in situ study of a wide range of reactions over supported metal and metal oxide catalysts.

\section{EXPERIMENTAL SECTION}

The $\mathrm{Co} / \mathrm{TiO}_{2}$ catalyst under study was synthetized by incipient wetness impregnation (IWI). For this purpose, a $\mathrm{TiO}_{2} \mathrm{P90}$ support (Evonik, $90 \%$ anatase and $10 \%$ rutile) was impregnated with a solution of $\mathrm{Co}\left(\mathrm{NO}_{3}\right)_{2} \times 6 \mathrm{H}_{2} \mathrm{O}$ (Acros Organics, 99+\%). The support was subsequently impregnated until the catalyst reached a final loading of 14.1 wt \%, which was confirmed by inductively coupled plasma atomic emission spectrometry (ICPAES). After impregnation, the catalyst powder was dried overnight at $333 \mathrm{~K}$ in a static air atmosphere, and then calcined for $4 \mathrm{~h}$ at $673 \mathrm{~K}$ under a $\mathrm{N}_{2}$ flow of $100 \mathrm{~mL} / \mathrm{min}$ (Linde, $\mathrm{N}_{2} \geq$ 99.999\%). Cobalt was present in the calcined catalyst in the form of $\mathrm{Co}_{3} \mathrm{O}_{4}$ nanocrystallites with an average size of $\sim 14 \mathrm{~nm}$. The average crystallite size was obtained by X-ray diffraction (XRD) analysis and confirmed by using scanning transmission electron microscopy-energy dispersion X-ray spectroscopy (STEMEDX). An in-depth characterization of the catalyst under study has been reported in the previous work, ${ }^{45}$ see Sections S3 and S4 in the Supporting Information. The in situ setup consists of a plug-flow reactor (capillary) horizontally mounted, with an outer diameter of $1 \mathrm{~mm}$ and inner diameter of $0.98 \mathrm{~mm}{ }^{46,47}$ The catalyst (with a particle size range of $150-90 \mu \mathrm{m}$ ) was placed and held by quartz wool in the isothermal zone of the plug-flow reactor. The capillary was heated by two IR heaters, and the temperature was controlled by a thermocouple placed on the bed of the plug-flow reactor. Section S5 presents the setup mounted in the XRS spectrometer and a schematic of the plugflow reactor. This type of reactors presents a more temperature homogeneous distribution compare to other setups systems that have been used and studied in our research group. ${ }^{48}$ During the in situ XRS/XRD experiments, two different types of experiments were performed:( a) an FTS reaction at $523 \mathrm{~K}$ and 5 bar over the $\mathrm{Co} / \mathrm{TiO}_{2}$ FTS catalyst, and (b) a carburization reaction of pure cobalt nanoparticles (i.e., $\mathrm{Co}_{3} \mathrm{O}_{4}$, Sigma-Aldrich 99.5\%) at $523 \mathrm{~K}$ and 5 bar. The in situ experiments contained two parts: (i) reduction (activation process, $\mathrm{Co}_{3} \mathrm{O}_{4} \rightarrow \mathrm{CoO} \rightarrow \mathrm{Co}^{0}$ ) of $\mathrm{Co}$ in a $\mathrm{H}_{2}$ atmosphere (Air Liquid, $\mathrm{H}_{2}>99.9995 \%$ ) by heating up to $673 \mathrm{~K}$ for $2 \mathrm{~h}$ and (ii) FTS/carburization reaction. Before
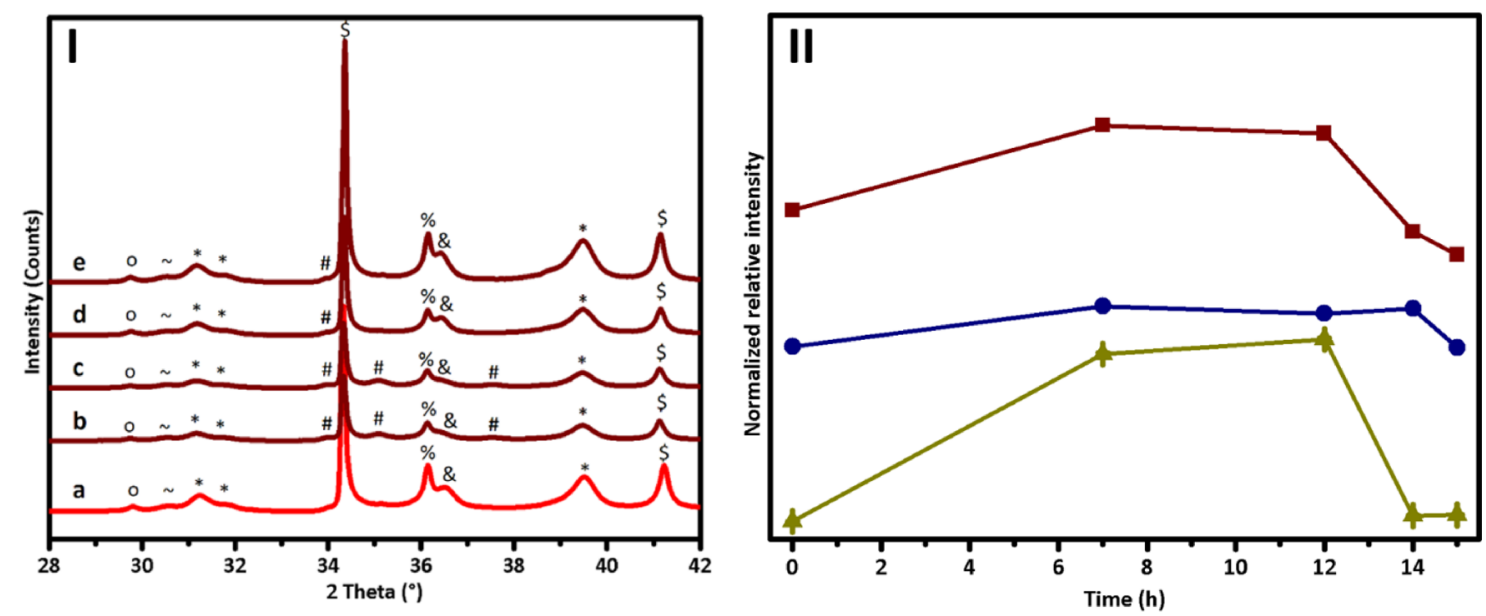

Figure 13. (I) In situ XRD patterns collected during the FTS reaction onto an unpromoted $\mathrm{Co} / \mathrm{TiO}_{2} \mathrm{FTS}$ catalyst at $523 \mathrm{~K}$ and 5 bar, using a $\mathrm{H}_{2}: \mathrm{CO}$ ratio of 0.5: (a) reduced catalyst, (b) $7 \mathrm{~h}$ of reaction, (c) $12 \mathrm{~h}$ of reaction, (d) $14 \mathrm{~h}$ of reaction, and (e) $15 \mathrm{~h}$ of reaction. Diffraction peaks of fcc-Co are marked with "\%" and hcp-Co with " $\&$ ", $\mathrm{Co}_{2} \mathrm{C}$ peaks are marked with "\#”, boron nitride peaks are marked with " $\$$ ”, $\mathrm{TiO}_{2}$ rutile peaks are marked with "o", $\mathrm{TiO}_{2}$ anatase peaks are marked with “*” and $\mathrm{CoTiO}_{3}$ peaks are marked with “ ". (II) Normalized relative intensity of the $\mathrm{Co}_{2} \mathrm{C}\left(35^{\circ}\right), \mathrm{fcc}^{-\mathrm{Co}}$ $\left(36.1^{\circ}\right)$, and hcp-Co $\left(36.5^{\circ}\right)$ species during the in situ FTS reaction. The instability of the carbide formed and the relative stability of the different cobalt metallic species presented during the reaction are confirmed. $\mathrm{Co}_{2} \mathrm{C}$ in yellow, fcc-Co in red, and hcp-Co in blue. Error bars are included in the plot for $\mathrm{Co}_{2} \mathrm{C}$. 
reduction, Co $\mathrm{L}_{2,3}$ edge and $\mathrm{C} \mathrm{K}$ edge spectra as well as XRD patterns were measured (at room temperature) to identify the different species presented in the catalyst before the activation process started. After the reduction of cobalt was achieved, a second set of measurements (i.e., Co $\mathrm{L}_{2,3}$ edge and $\mathrm{C} \mathrm{K}$ edge spectra as well as XRD patterns) were acquired to establish the changes experienced by the catalyst during the reduction process. Then, the reactor was cooled down from $673 \mathrm{~K}$ (reduction temperature) to room temperature (RT), and was exposed to a pure CO flow $(1 \mathrm{~mL} / \mathrm{min}$, Air Liquid, $\mathrm{CO}>$ 99.997\%) in the case of the carburization reaction, and to a mixture of $\mathrm{H}_{2}$ : $\mathrm{CO}$ (ratio of $0.5,0.5 \mathrm{~mL} / \mathrm{min}$ of $\mathrm{H}_{2}$ and $1 \mathrm{~mL} /$ min of $\mathrm{CO}$ ) in the case of FTS reaction followed by the pressurization of the system to 5 bar. After the pressurization process was finished, the temperature in the reactor was increased with a heating rate of $5 \mathrm{~K} / \mathrm{min}$ for both reactions. The measurements were performed at reaction conditions. The FTS and carburization reactions were completed after 15 and $10 \mathrm{~h}$, respectively. Additionally, ex situ measurements of Co and $\mathrm{C}$ reference materials were performed; $\mathrm{Co}_{3} \mathrm{O}_{4}, \mathrm{CoO}$ (Acros Organics, 99+ \%), $\mathrm{CoTiO}_{3}$ (Alfa Aesar, 99.8\%), Co (Co foil, 99.9\%), pyrene (Sigma-Aldrich, 98\%), graphite (SigmaAldrich), SX-70 (Shell) and SX-100 (Shell), and SX-70 and SX-100 are the FTS products (waxes). The catalytic activity of the $\mathrm{Co} / \mathrm{TiO}_{2}$ FTS catalyst was previously tested by using a fixedbed reactor, ${ }^{15}$ see Supporting Information, Section S6. Finally, the graphite and $\mathrm{Co}_{2} \mathrm{C}$ carbon $\mathrm{K}$-edge XANES spectra were calculated using FEFF9 $^{41}$ using input and crystallographic information files (CIF) from materialsproject.org. ${ }^{42,43}$ In both cases, the calculations were done in the reciprocal space, with core-hole taken into account within the random phase approximation and Hedin-Lundqvist exchange-correlation potential. A constant Gaussian broadening of $1 \mathrm{eV}$ was applied to the computed spectra to account for a combined effect of core-hole lifetime broadening and the experimental resolution (the latter one being the dominant one). The k-space grid was $13 \times 9 \times 9$ for $\mathrm{Co}_{2} \mathrm{C}$ and $15 \times 15 \times 5$ for graphite.

\section{ASSOCIATED CONTENT}

\section{SI Supporting Information}

The Supporting Information is available free of charge at https://pubs.acs.org/doi/10.1021/acscatal.0c04509.

Error calculation, the full XRS spectrum for the FTS experiment, the characterization of the $\mathrm{Co} / \mathrm{TiO}_{2} \sim 14 \mathrm{wt}$ $\%$ catalysts, and the catalytic test at different reaction conditions (PDF)

\section{AUTHOR INFORMATION}

\section{Corresponding Authors}

Frank M. F. de Groot - Inorganic Chemistry and Catalysis, Debye Institute for Nanomaterials Science, Utrecht University, 3584 CG Utrecht, The Netherlands; 10 orcid.org/00000002-1340-2186; Email: F.M.F.deGroot@uu.nl

Simo Huotari - Department of Physics, University of Helsinki, FI-00014 Helsinki, Finland; Email: simo.huotari@helsinki.fi

\section{Authors}

José G. Moya-Cancino - Inorganic Chemistry and Catalysis, Debye Institute for Nanomaterials Science, Utrecht University, 3584 CG Utrecht, The Netherlands; 10 orcid.org/00000002-5825-1553
Ari-Pekka Honkanen - Department of Physics, University of Helsinki, FI-00014 Helsinki, Finland

Ad M. J. van der Eerden - Inorganic Chemistry and Catalysis, Debye Institute for Nanomaterials Science, Utrecht University, 3584 CG Utrecht, The Netherlands

Ramon Oord - Inorganic Chemistry and Catalysis, Debye Institute for Nanomaterials Science, Utrecht University, 3584 CG Utrecht, The Netherlands

Matteo Monai - Inorganic Chemistry and Catalysis, Debye Institute for Nanomaterials Science, Utrecht University, 3584 CG Utrecht, The Netherlands; (0) orcid.org/0000-00016945-4391

Iris ten Have - Inorganic Chemistry and Catalysis, Debye Institute for Nanomaterials Science, Utrecht University, 3584 CG Utrecht, The Netherlands

Christoph J. Sahle - Beamline ID20, European Synchrotron Radiation Facility, 38043 Grenoble Cedex 9, France

Florian Meirer - Inorganic Chemistry and Catalysis, Debye Institute for Nanomaterials Science, Utrecht University, 3584 CG Utrecht, The Netherlands

Bert M. Weckhuysen - Inorganic Chemistry and Catalysis, Debye Institute for Nanomaterials Science, Utrecht University, 3584 CG Utrecht, The Netherlands; 이이.org/00000001-5245-1426

Complete contact information is available at: https://pubs.acs.org/10.1021/acscatal.0c04509

\section{Author Contributions}

F.d.G., S.H., and J.M.-C. formulated the idea and wrote the proposal for beamtime at the European Synchrotron Radiation Facility (ESRF). J.M.-C. prepared the catalyst used in this research and designed the experiments. S.H., J.M.-C., A.-P.H., A.v.d.E., R.O., and M.M. performed the different experiments. I.t.H. performed one of the catalytic tests. S.H. and J.M.-C. analyzed the obtained data. J.M.-C., S.H., and F.d.G. wrote the manuscript. F.M. and B.W. made revisions and corrections to the manuscript.

\section{Funding}

Shell Global Solutions and NWO-CHIPP grant and Academy of Finland (grant no. 1295696).

\section{Notes}

The authors declare no competing financial interest.

\section{ACKNOWLEDGMENTS}

Boyang Liu, Pasi Paalanen, Hebatalla Elnaggar, Ru-Pan Wang, and Herrick Schaink, all from Utrecht University, are acknowledged for their help during the preparation for the beamtime. Shell Global Solutions and a NWO-CHIPP grant are gratefully acknowledged for their financial support. S.H. and A.-P.H. were supported by the Academy of Finland (grant no. 1295696). The research presented in this document was carried out in European Synchrotron Radiation Facility (ESRF), Grenoble, France.

\section{ABBREVIATIONS}

FTS, Fischer-Tropsch synthesis; XRS, X-ray Raman scattering spectroscopy; XRD, X-ray diffraction; ELNES, electron energyloss near-edge spectroscopy; ESRF, European Synchrotron Radiation Facility; hcp, hexagonal close-packed; fcc, facecentered cubic; IWI, incipient wetness impregnation; ICPAES, inductively coupled plasma-atomic emission spectrometry; STEM-EDX, scanning transmission electron microscopy-energy 
dispersion X-ray spectroscopy; RT, room temperature; GC, gas chromatograph

\section{REFERENCES}

(1) de Smit, E.; Weckhuysen, B. M. The renaissance of iron-based Fischer-Tropsch synthesis: on the multifaceted catalyst deactivation behaviour. Chem. Soc. Rev. 2008, 37, 2758-2781.

(2) Cats, K. H.; Gonzalez-Jimenez, I. D.; Liu, Y.; Nelson, J.; van Campen, D.; Meirer, F.; van der Eerden, A. M. J.; de Groot, F. M. F.; Andrews, J. C.; Weckhuysen, B. M. X-ray nanoscopy of cobalt FischerTropsch catalysts at work. Chem. Commun. 2013, 49, 4622-4624.

(3) Cats, K. H.; Andrews, J. C.; Stéphan, O.; March, K.; Karunakaran, C.; Meirer, F.; de Groot, F. M. F.; Weckhuysen, B. M. Active phase distribution changes within a catalyst particle during Fischer-Tropsch synthesis as revealed by multi-scale microscopy. Catal. Sci. Technol. 2016, 6, 4438-4449.

(4) Tsakoumis, N. E.; Rønning, M.; Borg, Ø.; Rytter, E.; Holmen, A. Deactivation of cobalt based Fischer-Tropsch catalysts: A review. Catal. Today 2010, 154, 162-182.

(5) Khodakov, A. Y.; Chu, W.; Fongarland, P. Advances in the Development of Novel Cobalt Fischer-Tropsch Catalysts for Synthesis of Long-Chain Hydrocarbons and Clean Fuels. Chem. Rev. 2007, 107, $1692-1744$

(6) Carvalho, A.; Ordomsky, V. V.; Luo, Y.; Marinova, M.; Muniz, A. R.; Marcilio, N. R.; Khodakov, A. Y. Elucidation of deactivation phenomena in cobalt catalyst for Fischer-Tropsch synthesis using SSITKA. J. Catal. 2016, 344, 669-679.

(7) Zhao, Y.-H.; Su, H.-Y.; Sun, K.; Liu, J.; Li, W.-X. Structural and electronic properties of cobalt carbide $\mathrm{Co}_{2} \mathrm{C}$ and its surface stability: Density functional theory study. Surf. Sci. 2012, 606, 598-604.

(8) Claeys, M.; Dry, M. E.; van Steen, E.; du Plessis, E.; van Berge, P.J.; Saib, A. M.; Moodley, D. J. In situ magnetometer study on the formation and stability of cobalt carbide in Fischer-Tropsch synthesis. J. Catal. 2014, 318, 193-202.

(9) Zhong, L.; Yu, F.; An, Y.; Zhao, Y.; Sun, Y.; Li, Z.; Lin, T.; Lin, Y.; Qi, X.; Dai, Y.; Gu, L.; Hu, J.; Jin, S.; Shen, Q.; Wang, H. Cobalt carbide nanoprisms for direct production of lower olefins from syngas. Nature 2016, 538, 84-87.

(10) Xiang, Y.; Kruse, N. Tuning the catalytic CO hydrogenation to straight- and long-chain aldehydes/alcohols and olefins/paraffins. Nat. Commun. 2016, 7, 13058.

(11) Chen, W.; Filot, I. A. W.; Pestman, R.; Hensen, E. J. M. Mechanism of Cobalt-Catalyzed CO Hydrogenation: 2. FischerTropsch Synthesis. ACS Catal. 2017, 7, 8061-8071.

(12) Craxford, S. R.; Rideal, E. K. 338. The Mechanism of the Synthesis of Hydrocarbons from Water Gas. J. Chem. Soc. 1939, 16041614.

(13) Gnanamani, M. K.; Jacobs, G.; Keogh, R. A.; Shafer, W. D.; Sparks, D. E.; Hopps, S. D.; Thomas, G. A.; Davis, B. H. FischerTropsch synthesis: Effect of pretreatment conditions of cobalt on activity and selectivity for hydrogenation of carbon dioxide. Appl. Catal., A 2015, 499, 39-46.

(14) Gnanamani, M. K.; Jacobs, G.; Shafer, W. D.; Sparks, D. E.; Hopps, S.; Thomas, G. A.; Davis, B. H. Low Temperature Water-Gas Shift Reaction Over Alkali Metal Promoted Cobalt Carbide Catalysts. Top. Catal. 2014, 57, 612-618.

(15) van Ravenhorst, I. K.; Vogt, C.; Oosterbeek, H.; Bossers, K. W.; Moya-Cancino, J. G.; van Bavel, A. P.; van der Eerden, A. M. J.; Vine, D.; de Groot, F. M. F.; Meirer, F.; Weckhuysen, B. M. Capturing the Genesis of an Active Fischer-Tropsch Synthesis Catalyst with Operando X-ray Nanospectroscopy. Angew. Chem., Int. Ed. 2018, 57, 11957-11962.

(16) Morales, F.; de Groot, F. M. F.; Glatzel, P.; Kleimenov, E.; Bluhm, H.; Hävecker, M.; Knop-Gericke, A.; Weckhuysen, B. M. In Situ X-ray Absorption of $\mathrm{Co} / \mathrm{Mn} / \mathrm{TiO}_{2}$ Catalysts for Fischer-Tropsch Synthesis. J. Phys. Chem. B 2004, 108, 16201-16207.

(17) Morales, F.; Grandjean, D.; Mens, A.; de Groot, F. M. F.; Weckhuysen, B. M. X-ray Absorption Spectroscopy of $\mathrm{Mn} / \mathrm{Co} / \mathrm{TiO}_{2}$ Fischer-Tropsch Catalysts: Relationships between Preparation
Method, Molecular Structure, and Catalyst Performance. J. Phys. Chem. B 2006, 110, 8626-8639.

(18) Kumar, N.; Payzant, E. A.; Jothimurugesan, K.; Spivey, J. J. Combined in situ XRD and in situ XANES studies on the reduction behavior of a rhenium promoted cobalt catalyst. Phys. Chem. Chem. Phys. 2011, 13, 14735-14741.

(19) Karaca, H.; Hong, J.; Fongarland, P.; Roussel, P.; GribovalConstant, A.; Lacroix, M.; Hortmann, K.; Safonova, O. V.; Khodakov, A. Y. In situ XRD investigation of the evolution of alumina-supported cobalt catalysts under realistic conditions of Fischer-Tropsch synthesis. Chem. Commun. 2010, 46, 788-790.

(20) Fischer, N.; Claeys, M. Phase changes studied under in situ conditions-A novel cell. Catal. Today 2016, 275, 149-154.

(21) Cats, K. H.; Weckhuysen, B. M. Combined Operando X-ray Diffraction/Raman Spectroscopy of Catalytic Solids in the Laboratory: The $\mathrm{Co} / \mathrm{TiO}_{2}$ Fischer-Tropsch Synthesis Catalyst Showcase. ChemCatChem 2016, 8, 1531-1542.

(22) Moya-Cancino, J. G.; Honkanen, A.-P.; van der Eerden, A. M. J.; Schaink, H.; Folkertsma, L.; Ghiasi, M.; Longo, A.; Meirer, F.; de Groot, F. M. F.; Huotari, S.; Weckhuysen, B. M. Elucidating the K-Edge X-Ray Absorption Near-Edge Structure of Cobalt Carbide. ChemCatChem 2019, 11, 3042-3045.

(23) Singh, J. A.; Hoffman, A. S.; Schumann, J.; Boubnov, A.; Asundi, A. S.; Nathan, S. S.; Nørskov, J.; Bare, S. R.; Bent, S. F. Role of $\mathrm{Co}_{2} \mathrm{C}$ in ZnO-promoted Co Catalysts for Alcohol Synthesis from Syngas. Chem CatChem 2019, 11, 799-809.

(24) Mohandas, J. C.; Gnanamani, M. K.; Jacobs, G.; Ma, W.; Ji, Y.; Khalid, S.; Davis, B. H. Fischer-Tropsch Synthesis: Characterization and Reaction Testing of Cobalt Carbide. ACS Catal. 2011, 1, 15811588 .

(25) Krisch, M. H.; Sette, F.; Masciovecchio, C.; Verbeni, R. Momentum Transfer Dependence of Inelastic X-Ray Scattering from the Li K Edge. Phys. Rev. Lett. 1997, 78, 2843-2846.

(26) Krisch, M.; Sette, F. X-ray Raman Scattering from Low Z Materials. Surf. Rev. Lett. 2002, 09, 969-976.

(27) Sahle, C. J.; Mirone, A.; Niskanen, J.; Inkinen, J.; Krisch, M.; Huotari, S. Planning, performing and analyzing X-ray Raman scattering experiments. J. Synchrotron Rad. 2015, 22, 400-409.

(28) Miedema, P. S.; Ngene, P.; van der Eerden, A. M. J.; Weng, T.-C.; Nordlund, D.; Sokaras, D.; Alonso-Mori, R.; Juhin, A.; de Jongh, P. E.; de Groot, F. M. F. In situ X-ray Raman spectroscopy of $\mathrm{LiBH}_{4}$. Phys. Chem. Chem. Phys. 2012, 14, 5581-5587.

(29) Miedema, P. S.; Ngene, P.; van der Eerden, A. M. J.; Sokaras, D.; Weng, T.-C.; Nordlund, D.; Au, Y. S.; de Groot, F. M. F. In situ X-ray Raman spectroscopy study of the hydrogen sorption properties of lithium borohydride nanocomposites. Phys. Chem. Chem. Phys. 2014, 16, 22651-22658.

(30) Huotari, S.; Sahle, C. J.; Henriquet, C.; Al-Zein, A.; Martel, K.; Simonelli, L.; Verbeni, R.; Gonzalez, H.; Lagier, M.-C.; Ponchut, C.; Moretti Sala, M.; Krisch, M.; Monaco, G. A large-solid-angle X-ray Raman scattering spectrometer at ID20 of the European Synchrotron Radiation Facility. J. Synchrotron Rad. 2017, 24, 521-530.

(31) Flynn, G. J.; Wirick, S.; Keller, L. P.; Jacobsen, C. STXM search for carbonate in samples of Comet 81P/Wild 2. J. Phys.: Conf. Ser. 2009, 186, No. 012085.

(32) Hitchcock, A. P.; Gas Phase Core Excitation Database; http:// unicorn.mcmaster.ca/corex/cedb-title.html, 2003.

(33) Hitchcock, A. P.; Mancini, D. C. Bibliography and database of inner shell excitation spectra of gas phase atoms and molecules. $J$. Electron Spectrosc. Relat. Phenom. 1994, 67, 1-vii.

(34) Hitchcock, A. P.; Brion, C. E. K-shell excitation spectra of CO, $\mathrm{N}_{2}$ and $\mathrm{O}_{2}$. J. Electron Spectrosc. Relat. Phenom. 1980, 18, 1-21.

(35) Zhou, J. G.; Wang, J.; Sun, C. L.; Maley, J. M.; Sammynaiken, R.; Sham, T. K.; Pong, W. F. Nano-scale chemical imaging of a single sheet of reduced graphene oxide. J. Mater. Chem. 2011, 21, 14622-14630.

(36) Braun, A.; Huggins, F. E.; Shah, N.; Chen, Y.; Wirick, S.; Mun, S. B.; Jacobsen, C.; Huffman, G. P. Advantages of soft X-ray absorption over TEM-EELS for solid carbon studies--a comparative study on diesel soot with EELS and NEXAFS. Carbon 2005, 43, 117-124. 
(37) de Smit, E.; Swart, I.; Creemer, J. F.; Hoveling, G. H.; Gilles, M. K.; Tyliszczak, T.; Kooyman, P. J.; Zandbergen, H. W.; Morin, C.; Weckhuysen, B. M.; de Groot, F. M. F. Nanoscale chemical imaging of a working catalyst by scanning transmission X-ray microscopy. Nature 2008, 456, 222-225.

(38) Cody, G. D.; Botto, R. E.; Ade, H.; Wirick, S. The application of soft X-ray microscopy to the in-situ analysis of sporinite in coal. Int. J. Coal Geol. 1996, 32, 69-86.

(39) Hitchcock, A. P.; Urquhart, S. G.; Rightor, E. G. Inner-Shell Spectroscopy of Benzaldehyde, Terephthalaldehyde, EthylBenzoate, Terephthaloyl Chloride, and Phosgene: Models for Core Excitation of Poly(ethylene terephthalate). J. Phys. Chem. 1992, 96, 8736-8750.

(40) Urbonaite, S.; Wachtmeister, S.; Mirguet, C.; Coronel, E.; Zou, W. Y.; Csillag, S.; Svensson, G. EELS studies of carbide derived carbons. Carbon 2007, 45, 2047-2053.

(41) Rehr, J. J.; Kas, J. J.; Vila, F. D.; Prange, M. P.; Jorissen, K. Parameter-free calculations of X-ray spectra with FEFF9. Phys. Chem. Chem. Phys. 2010, 12, 5503-5513.

(42) Jain, A.; Ong, S. P.; Hautier, G.; Chen, W.; Richards, W. D.; Dacek, S.; Cholia, S.; Gunter, D.; Skinner, D.; Ceder, G.; Persson, K. A. Commentary: The Materials Project: A materials genome approach to accelerating materials innovation. APL Mater. 2013, 1, No. 011002.

(43) Mathew, K.; Zheng, C.; Winston, D.; Chen, C.; Dozier, A.; Rehr, J. J.; Ong, S. P.; Persson, K. A. High-throughput computational X-ray absorption spectroscopy. Sci. Data 2018, 5, 180151.

(44) Huotari, S.; Pylkkänen, T.; Verbeni, R.; Monaco, G.; Hämäläinen, K. Direct tomography with chemical-bond contrast. Nat. Mater. 2011, 10, 489-493.

(45) Moya-Cancino, J. G.; Honkanen, A.-P.; van der Eerden, A. M. J.; Schaink, H.; Folkertsma, L.; Ghiasi, M.; Longo, A.; de Groot, F. M. F.; Meirer, F.; Huotari, S.; Weckhuysen, B. M. In-situ X-Ray Absorption Near Edge Structure Spectroscopy of a Solid Catalyst using a Laboratory-Based Set-up. ChemCatChem 2019, 11, 1039-1044.

(46) Fischer, N.; Clapham, B.; Feltes, T.; Claeys, M. Cobalt-Based Fischer-Tropsch Activity and Selectivity as a Function of Crystallite Size and Water Partial Pressure. ACS Catal. 2015, 5, 113-121.

(47) Fischer, N.; Clapham, B.; Feltes, T.; van Steen, E.; Claeys, M. Size-Dependent Phase Transformation of Catalytically Active Nanoparticles Captured In Situ. Angew. Chem. 2014, 53, 1342-1345.

(48) van Ravenhorst, I. K.; Geitenbeek, R. G.; van der Eerden, A. M. J.; van Omme, J. T.; Peréz Garza, H. H.; Meirer, F.; Meijerink, A.; Weckhuysen, B. M. In Situ Local Temperature Mapping in Microscopy Nano-Reactors with Luminescence Thermometry. ChemCatChem 2019, 11, 5505-5512. 